\title{
The effects of illumination on the acquisition of delayed matching-to-sample
}

\author{
DONALD F. KENDRICK, JR., DANIEL K. TRANBERG, and MARK RILLING \\ Michigan State University, East Lansing, Michigan 48824
}

\begin{abstract}
Illumination effects during steady-state performance of discrimination tasks in animals have been well documented, whereas research on illumination effects during acquisition has been largely ignored. Exceptions to this rule are Wasserman's (1973) autoshaping experiments and Maki's (1979) successive discrimination experiment. The present experiment investigated the effects of illumination changes on acquisition of a conditional discrimination-delayed matchingto-sample (DMTS). Pigeons were used in a between-groups design which factorially varied houselight illumination, on or off, during the presentations of DMTS stimuli, the delay interval, and the intertrial interval (ITI). DMTS performance over five blocks of sessions was the dependent variable. The major result was the three-way interaction of sessions, the intertrial interval, and the DMTS stimuli. Constant illumination resulted in the highest discrimination ratios over the last four blocks of sessions. A constant dark condition did not differ from a condition with dark ITIs and illuminated stimulus presentations or from a condition with illuminated ITIs and dark stimulus presentations. The proffered explanation of these data emphasizes the disruptive effects of stimulus changes and Wasserman's (1973) cue localization hypothesis. The loci of the stimulus change and cue localization effect are suggested to be either at the beginning of a trial or at the end of a trial. A pretrial account emphasizes the role of stimulus changes on the encoding of the sample stimulus, and a posttrial account emphasizes the role of stimulus changes during consolidation processing.
\end{abstract}

A number of experiments have investigated the disruption of delayed matching-to-sample performance produced by illuminated delay intervals (D'Amato \& O'Neil, 1971; Etkin, 1972; Grant \& Roberts, 1976; Shimp \& Moffitt, 1977; Zentall, 1973). With monkeys, D'Amato and his colleagues have found that increasing the ambient illumination during the delay intervals of delayed matching-to-sample (DMTS) reduces matching accuracy and that maintaining a dark delay interval does not reduce matching accuracy. With pigeons, Grant and Roberts (1976) found that both ambient and local sources of illumination disrupted DMTS performance in direct proportion to the amount of interpolated illumination.

Tranberg and Rilling (1980) noted that DMTS test sessions in these and other studies (e.g., D'Amato \& O’Neil, 1971; Roberts \& Grant, 1978) included changes in delay interval illumination from that prevailing during acquisition and steady state. This led them to propose that changes in illumination between baseline and testing may have disrupted performance, as opposed to D'Amato's (1973) assumption that interpolated illumination per se degrades performance.

Special thanks are extended to Tom Stonebraker for his helpful comments and discussion during the course of this work. Requests for reprints should be addressed to Donald F. Kendrick, Michigan State University, Department of Psychology, Psychology Research Building, East Lansing, Michigan 48824. Daniel K. Tranberg is now at Hillcrest Regional Center for Developmental Disabilities, Howell, Michigan.
They subsequently demonstrated that both dark and light delay intervals during test sessions resulted in disruption of DMTS performance when they differed from baseline delay interval illumination. Cook (1980) has independently verified this illumination change effect. Delay-interval illumination changes thus appear to be a powerful source of interference in the steady-state performance of delayed matching-tosample in mammalian (monkeys) and avian (pigeons) species.

There have been no systematic studies of the effects of delay-interval illumination on the acquisition of DMTS. However, there are three areas that suggest that illumination manipulations may affect acquisition performance. First, inspection of Tranberg and Rilling's (1980) Figure 1 reveals that acquisition of their baseline criterion was slower when there were changes in illumination during a DMTS trial. That is, when intertrial interval (ITI) and delay interval illumination differed, four out of six pigeons required more than 50 sessions to reach criterion; when ITI and delay interval illumination did not differ, only one of five pigeons required more than 50 sessions to achieve criterion. This difference suggests that changes in illumination conditions correlated with changes in trial events, for example, from light during ITIs to dark during delay intervals, have an adverse effect on acquisition of DMTS.

A second area suggesting that illumination changes affect acquisition performance is Wagner's (1979) 
model of animal memory in which stimulus changes may have deleterious effects on information processing. In this model, stimuli compete for space in a limited-capacity short-term rehearsal buffer. Stimulus change is considered to be the primary agent, causing displacement from this buffer. This suggests that learning is enhanced with constant stimulus conditions as opposed to changing stimulus conditions. Wagner's model therefore predicts that constant illumination conditions among trial events (DMTS stimuli, delay intervals) and the ITI may enhance conditioning and that changing illumination conditions may retard conditioning.

Third, the effects of illumination conditions on acquisition of autoshaping have been investigated (Wasserman, 1973; also reported in Hearst, 1975, p. 225 , and in Hearst \& Jenkins, 1974, p. 9). It was found that acquisition was slower in a dark operant chamber relative to an illuminated chamber (cf. Rescorla \& Wagner, 1972; Tomie, Murphy, Fash, \& Jackson, 1980). Wasserman developed the cue localization hypothesis to account for this finding. He hypothesized that presenting the keylight stimuli in a darkened chamber provided ambient illumination, that is, additional visual stimuli correlated with reinforcement, and that acquisition was retarded because of stimulus competition between the target keylight stimulus and background or contextual stimuli. In a chamber always illuminated by the houselight, the ambient illumination from the keylights was negated, thereby reducing stimulus competition and enhancing acquisition of stimulus control by the localized keylight. Wasserman's research suggests that presentation of DMTS stimuli in an illuminated chamber produces superior conditioning relative to the presentation of DMTS stimuli in a darkened chamber.

The purpose of the present experiment was to assess the effects of systematic illumination changes on the acquisition of a successive DMTS task. This experiment factorially varied houselight illumination, on or off, during DMTS trial events: presentation of the sample and comparison stimuli, the delay inter$\mathrm{val}$, and the intertrial interval. Delayed matchingto-sample performance over five blocks of sessions was the dependent variable.

\section{METHOD}

\section{Subjects}

Sixty-four adult White Carneaux pigeons, maintained within $\pm 20 \mathrm{~g}$ of $80 \%$ of their free-feeding weights, served as subjects. They were individually housed in a temperature-controlled and constantly illuminated room and had constant access to grit and water. The pigeons were assigned to eight groups of eight and were run 5 to 6 days per week.

\section{Apparatus}

The pigeons acquired DMTS in a homemade two-key operant chamber, $30 \times 30 \times 34 \mathrm{~cm}$. The two $2.5-\mathrm{cm}$ response keys were centered above a $5 \times 6 \mathrm{~cm}$ magazine opening. Only the left key, which required $15 \mathrm{~g}(.15 \mathrm{~N})$ for activation, was used. An IEE projector (Model 0010-01-0393-44) transilluminated the key with a red $(606 \mathrm{~nm})$ or green $(555 \mathrm{~nm})$ stimulus. A $28-\mathrm{V}$ (CM-1829) bulb illuminated the magazine enclosure during 2.5 -sec access to mixed grain reinforcements. The $28-\mathrm{V}$ houselight (GE-757) was centered on the ceilings of the chamber within a translucent glass housing. The chamber was housed within a homemade soundproof enclosure with a ventilation fan that provided masking noise. Experimental events were controlled by standard electromechanical programming equipment located in an adjacent room.

\section{Procedure}

Birds were magazine trained and autoshaped in a lighted operant chamber. Each bird was placed in the chamber with the food hopper elevated, the magazine enclosure lighted and filled with mixed grain. The houselight was extinguished during the $302.5-\mathrm{sec}$ reinforcement periods, which were separated by an intertrial interval of $30 \mathrm{sec}$. Following magazine training, each bird received two or three sessions of 60 autoshaping trials. Red and green keylight stimuli were programmed to occur equally often every $40 \mathrm{sec}$ on a pseudorandom basis. Each stimulus lasted $5 \mathrm{sec}$ and terminated with $2.5 \mathrm{sec}$ of reinforcement during which the houselight was extinguished. Two autoshaping sessions were required; if the birds were not pecking reliably, a third session was given.

The pigeons were then placed on a successive DMTS task with 1-sec delay intervals. A single response key was used to present four types of trials: red-red, green-green, red-green, and greenred. The first stimulus of each trial, the sample, lasted a minimum of $5 \mathrm{sec}$, after which a single keypeck terminated the sample and initiated the 1-sec delay interval. The second stimulus, the comparison, lasted a minimum of $5 \mathrm{sec}$ and, on matching trials (i.e., red-red and green-green), a single keypeck after the $5 \mathrm{sec}$ resulted in reinforcement and an associated blackout. The blackout alone automatically occurred on red-green and green-red trials after the $5 \mathrm{sec}$ elapsed. Twenty-five sessions consisted of 96 trials, presented in a different pseudorandom order each session, with a 25-sec ITI. Restrictions on the pseudorandom order were that no more than three reinforced or nonreinforced trials could occur consecutively. Illumination conditions were imposed from the first DMTS session. Eight birds were unsystematically assigned to each of the eight conditions designated in Table 1. As Table 1 shows, the houselight was either on or of during the DMTS trial events. Note that illumination conditions were always the same during sample and comparison stimuli.

Responses during each stimulus, during the delay intervals, and during the ITI were recorded each session. Responses that terminated the sample stimuli and responses that terminated the matching stimuli on reinforced trials were excluded from analysis. The dependent variable of primary interest was a discrimination ratio calculated by dividing the number of responses to matching comparison stimuli by the sum of the number of responses to

Table 1

Illumination Conditions, Houselight On (O) or Off (X)

\begin{tabular}{cccc}
\hline Group & ITI & $\begin{array}{c}\text { DMTS } \\
\text { Stimuli }\end{array}$ & $\begin{array}{c}\text { Delay } \\
\text { Interval }\end{array}$ \\
\hline LLL & $\mathrm{O}$ & $\mathrm{O}$ & $\mathrm{O}$ \\
LLD & $\mathrm{O}$ & $\mathrm{O}$ & $\mathrm{X}$ \\
LDL & $\mathrm{O}$ & $\mathrm{X}$ & $\mathrm{O}$ \\
LDD & $\mathrm{O}$ & $\mathrm{X}$ & $\mathrm{X}$ \\
DLL & $\mathrm{X}$ & $\mathrm{O}$ & $\mathrm{O}$ \\
DLD & $\mathrm{X}$ & $\mathrm{O}$ & $\mathrm{X}$ \\
DDL & $\mathrm{X}$ & $\mathrm{X}$ & $\mathrm{O}$ \\
DDD & $\mathrm{X}$ & $\mathrm{X}$ & $\mathrm{X}$ \\
\hline
\end{tabular}

Note-Three-letter group codes indicate illumination during ITIs, stimulus presentations, and delay intervals. The illumination conditions during sample and comparison stimuli were always the same. 
matching and nonmatching comparison stimuli and multiplying by 100 . A ratio of $50 \%$ indicates an equal number of responses to matching and nonmatching stimuli, and a ratio of $100 \%$ indicates no responses to the nonmatching stimuli.

\section{RESULTS}

Figure 1 shows the mean discrimination ratios per block of five sessions for all eight groups. The dotted line across each panel indicates discrimination ratios of $70 \%$. Figure 1 shows that all eight groups performed similarly on the first block of five sessions, but that Groups LLL and LLD ended with higher matching accuracies than the other groups. The top four panels show that Groups LLL, LLD, DLL, and DLD reached or surpassed $70 \%$, while the bottom four panels show that Groups LDL, LDD, DDL, and DDD performed below $70 \%$. These data were sub-

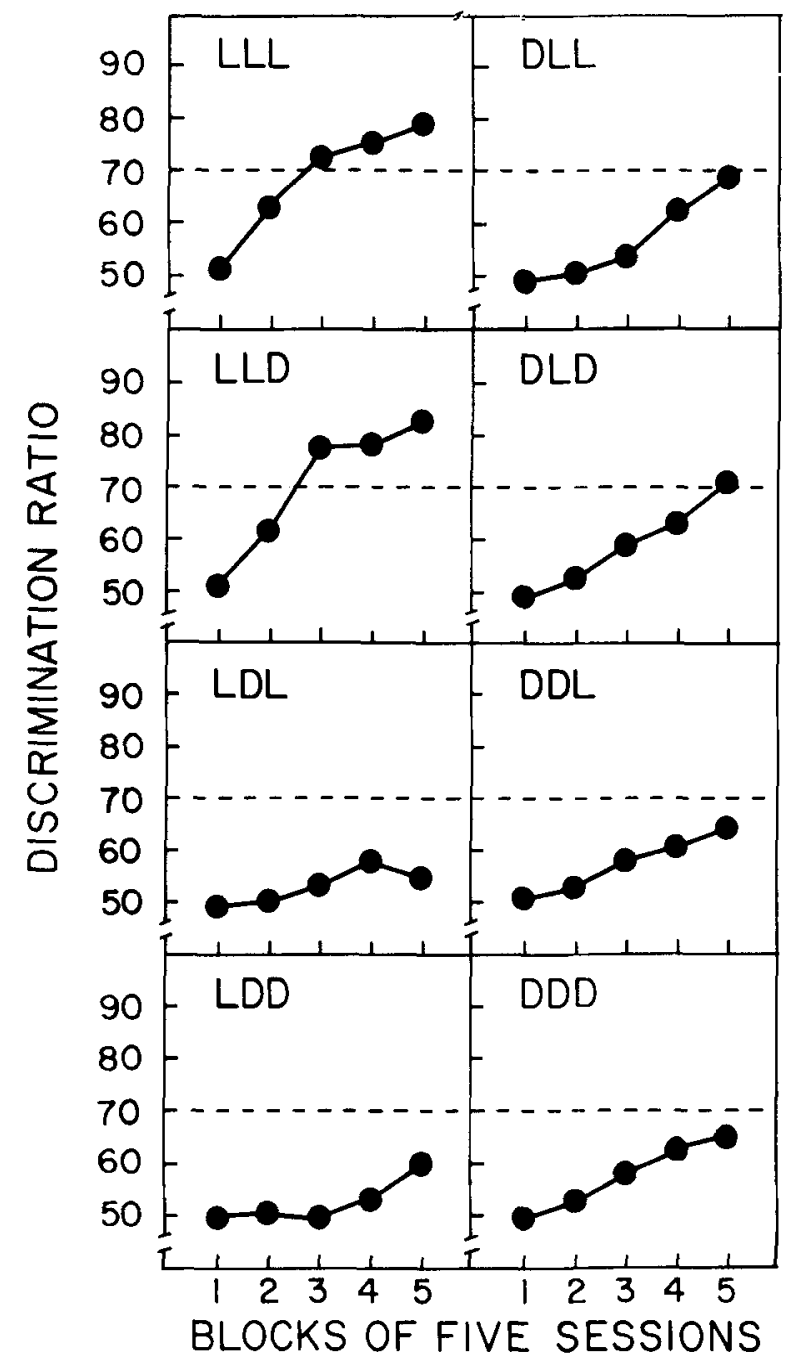

Figure 1. Mean discrimination ratios per five-session blocks. Each panel presents the acquisition data of a single group. The dotted line at $70 \%$ is to facilitate group comparisons. See Table 1 for the definitions of the group acronyms.

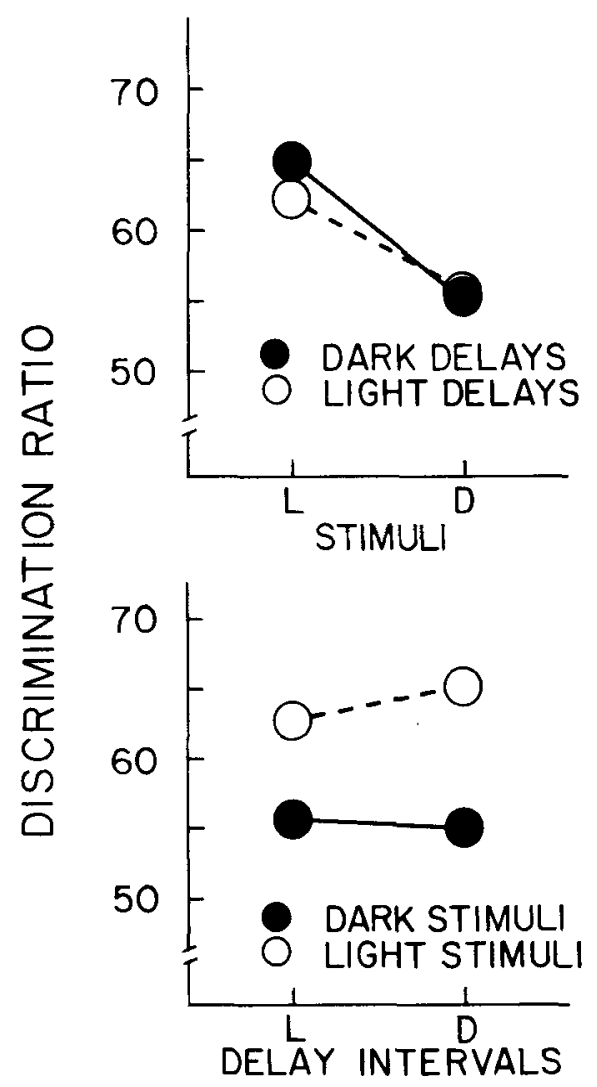

Figure 2. Simple effects of the Stimulus Presentations by Delay Intervals interaction. Data are plotted as a function of the stimuli, top panel, and as a function of the delay intervals, bottom panel. $\mathrm{L}=$ houselight on, $\mathrm{D}=$ houselight off.

jected to a split-plot factorial analysis of variance, with sessions as a repeated measure (Kirk, 1968, p. 244).

The higher order significant interactions were: Delay Interval Illumination by Stimulus Presentations Illumination $[F(1,56)=6.25, \mathrm{p}<.01]$ and Intertrial Interval Illumination by Sessions by Stimulus Presentations Illumination $[F(4,224)=4.02, p<.01]$. The following interactions were not significant $(\mathrm{Fs}<1)$ : Intertrial Intervals by Stimulus Presentations by Delay Intervals, Intertrial Intervals by Sessions by Delay Intervals, Sessions by Stimulus Presentations by Delay Intervals, Intertrial Intervals by Stimulus Presentations by Delay Intervals, and Sessions by Intertrial Intervals by Stimulus Presentations by Delay Intervals.

Figure 2 shows the simple effects of the Delay Interval Illumination by Stimulus Presentation Illumination interaction. In the top panel, discrimination ratios under light and dark delay conditions are plotted as a function of DMTS stimulus presentation conditions. As the top panel indicates, DMTS performance was better with light stimuli whether the delays were dark $[F(1,56)=172.74, p<.01]$ or light $[F(1,56)=92.28, p<.01]$. The bottom panel on Fig- 
ure 2 shows discrimination ratios under dark and light DMTS stimulus presentation conditions as a function of delay interval illumination conditions. Dark delays with light stimuli resulted in faster acquisition than light delays with light stimuli $[F(1,56)=$ $11.70, \mathrm{p}<.01]$, whereas DMTS performance with dark delay intervals and dark stimuli did not differ from performance with light delay intervals and dark stimuli $(F<1)$. Therefore, delay interval darkness produced faster acquisition only when the operant chamber was illuminated during stimulus presentations.

Figure 3 shows acquisition as a function of illumination condition during the ITI and illumination condition during the DMTS stimuli. As Figure 3 indicates, light during the ITI with light during the stimuli (LL) resulted in superior DMTS acquisition, while the other three combinations produced similar, but retarded, acquisition. The first block of five sessions failed to show a significant interaction among ITI and stimulus presentation $(F<1)$. The ITI by Stimulus Presentations interaction was significant and consistent across the remaining blocks of sessions [second block, $\mathrm{F}(4,280)=2.82, \mathrm{p}<.05$; third block, $F(4,280)=9.51, p<.01$; fourth block, $F(4,280)$ $=7.14, \mathrm{p}<.01 ;$ fifth block, $\mathrm{F}(4,280)=2.57, \mathrm{p}<.05]$.

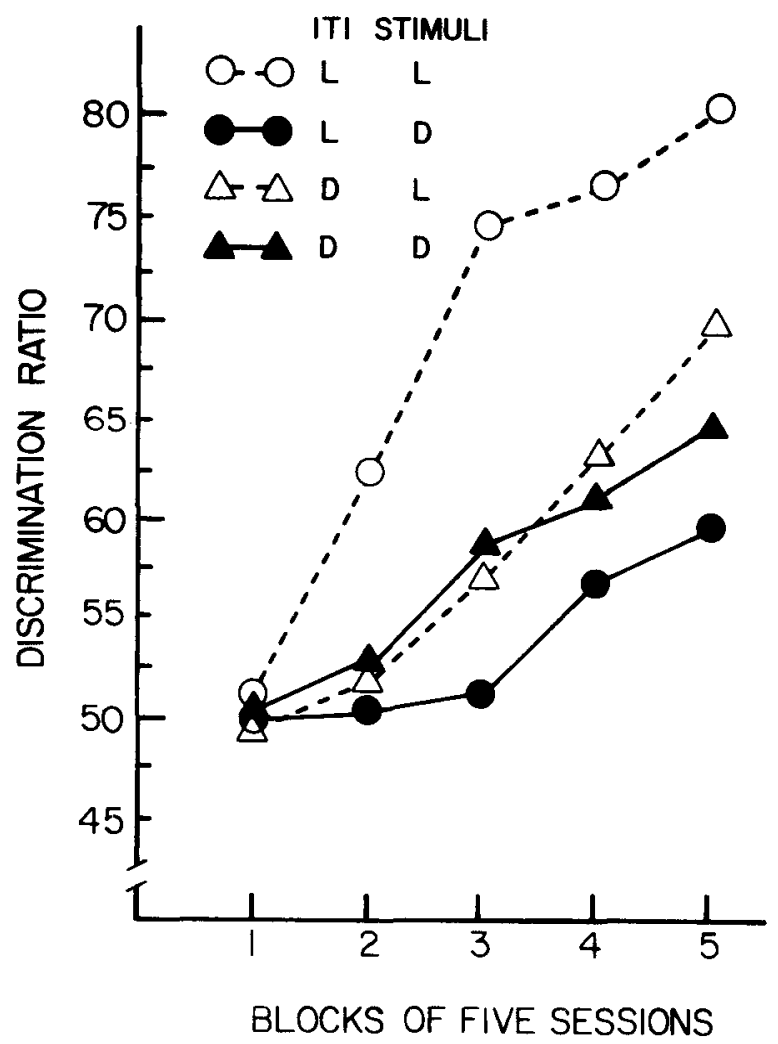

Figure 3. Acquisition rates of the groups collapsed across delayinterval illumination. LL is significantly superior to the other groups. LD and DL differ only at the fifth block of sessions.
Analysis of the simple effects of the illumination conditions of ITI and stimulus presentations shows that a light ITI with light stimulus presentations (LL) enhanced performance relative to a dark ITI with light stimulus presentations (DL) in the last three blocks of sessions (LL $>$ DL) [first block, $F<1$; second block, $\mathrm{F}(4,280)=1.05, \mathrm{p}<.05$; third block, $F(4,280)=10.43, p<.01$; fourth block, $F(4,280)=$ $7.63, \mathrm{p}<.01$; fifth block, $\mathrm{F}(4,280)=3.57, \mathrm{p}<.01$ ] Light ITIs with dark stimuli (LD) and dark ITIs with dark stimuli (DD) did not significantly differ within any blocks of sessions (LD = DD) [first block, $F<1$; second block, $F<1$; third block, $F(4,280)=1.50$, $\mathrm{p}>.05$; fourth block, $\mathrm{F}(4,280)=1.03, \mathrm{p}>.05$; fifth block, $F(4,280)=1.64, p>.05$ ]. Conditioning was enhanced with light ITIs and light stimulus presentations (LL) compared with light ITIs and dark stimuli (LD) during the last 20 sessions ( $L L>L D$ ) [first block, $\mathrm{F}<1$; second block, $\mathrm{F}(4,280)=4.54, \mathrm{p}<.01$; third block, $F(4,280)=16.86, p<.01$; fourth block, $F(4,280)=16.49, p<.01$; fifth block, $F(4,280)=$ 16.44, $\mathrm{p}<.01$ ]. Also, dark ITIs with light stimuli (DL) did not differ from dark ITIs with dark stimuli (DD) except in the last block of sessions. In this last block, dark ITIs with light stimuli (DL) resulted in better performance than dark ITIs with dark stimuli $(\mathrm{DL}>\mathrm{DD})[\mathrm{F}(4,280)=62.41, \mathrm{p}<.01]$. These data show that $L L$ resulted in the most superior performance of all conditions and that performance in the DL condition was better than performance in the DD and $L D$ conditions in the last block of sessions only.

Table 2 presents the mean responses per minute for all eight groups across all trial events. From this table, it can be seen that response rates are unsystematically related to group treatments, except of course for the rate to the comparison stimuli. Generally, response rates to nonmatching comparison stimuli declined over trials, whereas rates to the matching comparison stimuli tended to remain constant or to increase slightly. Overall, response rates increased from the first block of sessions to the last during all events except the comparison stimuli.

Table 3 presents the mean responses per minute for the four conditions of the Stimulus Presentations by Delay Interval interaction. From this table, it can be seen that when delay interval illumination differed from the illumination conditions during the stimulus presentations, response rate was lower than when illumination conditions did not differ between the stimuli and the delays. Also, in general, response rate tended to increase across sessions during all trial events, except the comparison stimuli. Table 4 presents the mean responses per minute for the four conditions of the Intertrial Interval by Stimulus Presentations by Sessions interaction. Table 4 shows that pecking to the sample stimuli was not a function of stimulus change as noted for delay interval pecking and that response rate was not correlated with match- 
Table 2

Responses per Minute: Means for Each Group Across All Trial Sequences and by Blocks of Five Sessions (B/S)

\begin{tabular}{|c|c|c|c|c|c|c|c|c|c|c|c|c|c|}
\hline $\mathrm{B} / \mathrm{S}$ & Red & Delay & Red & Green & Delay & Green & Red & Delay & Green & Green & Delay & Red & ITI \\
\hline \multicolumn{14}{|c|}{ Group LLL } \\
\hline $\begin{array}{l}1 \\
2 \\
3 \\
4 \\
5\end{array}$ & $\begin{array}{l}150.4 \\
171.5 \\
166.6 \\
157.2 \\
174.9\end{array}$ & $\begin{array}{l}104.5 \\
157.4 \\
234.3 \\
260.0 \\
274.3\end{array}$ & $\begin{array}{l}212.40 \\
246.00 \\
241.00 \\
248.50 \\
255.60\end{array}$ & $\begin{array}{l}140.9 \\
159.7 \\
158.8 \\
157.2 \\
160.9\end{array}$ & $\begin{array}{l}111.7 \\
183.0 \\
234.8 \\
273.8 \\
382.9\end{array}$ & $\begin{array}{l}217.4 \\
259.9 \\
233.1 \\
244.2 \\
251.5\end{array}$ & $\begin{array}{l}150.6 \\
172.5 \\
170.1 \\
162.1 \\
174.9\end{array}$ & $\begin{array}{l}121.4 \\
189.1 \\
234.0 \\
259.2 \\
277.7\end{array}$ & $\begin{array}{r}199.8 \\
139.0 \\
101.8 \\
89.3 \\
79.2\end{array}$ & $\begin{array}{l}142.2 \\
160.4 \\
156.1 \\
155.5 \\
161.9\end{array}$ & $\begin{array}{l}119.8 \\
181.3 \\
245.8 \\
277.2 \\
286.8\end{array}$ & $\begin{array}{r}212.0 \\
171.2 \\
108.9 \\
90.6 \\
82.4\end{array}$ & $\begin{array}{l}.8 \\
1.1 \\
2.3 \\
4.1 \\
6.9\end{array}$ \\
\hline \multicolumn{14}{|c|}{ Group LLD } \\
\hline $\begin{array}{l}1 \\
2 \\
3 \\
4 \\
5\end{array}$ & $\begin{array}{r}82.7 \\
86.5 \\
106.9 \\
131.1 \\
131.9\end{array}$ & $\begin{array}{l}69.6 \\
73.9 \\
78.5 \\
84.2 \\
82.2\end{array}$ & $\begin{array}{l}140.30 \\
187.70 \\
161.40 \\
211.80 \\
203.00\end{array}$ & $\begin{array}{r}77.2 \\
104.1 \\
100.8 \\
123.9 \\
128.9\end{array}$ & $\begin{array}{l}70.7 \\
73.4 \\
75.1 \\
79.8 \\
78.6\end{array}$ & $\begin{array}{l}142.1 \\
187.4 \\
207.8 \\
211.5 \\
210.8\end{array}$ & $\begin{array}{r}84.0 \\
91.7 \\
107.5 \\
124.7 \\
129.2\end{array}$ & $\begin{array}{l}72.1 \\
74.2 \\
75.0 \\
81.2 \\
82.2\end{array}$ & $\begin{array}{r}134.6 \\
118.7 \\
56.7 \\
55.7 \\
48.0\end{array}$ & $\begin{array}{r}139.8 \\
62.4 \\
93.7 \\
115.0 \\
113.5\end{array}$ & $\begin{array}{l}72.4 \\
71.6 \\
78.2 \\
82.0 \\
65.9\end{array}$ & $\begin{array}{r}101.6 \\
75.3 \\
48.7 \\
25.9 \\
32.0\end{array}$ & $\begin{array}{l}.4 \\
.1 \\
.1 \\
.1 \\
.1\end{array}$ \\
\hline \multicolumn{14}{|c|}{ Group LDL } \\
\hline $\begin{array}{l}1 \\
2 \\
3 \\
4 \\
5\end{array}$ & $\begin{array}{r}116.6 \\
99.4 \\
124.2 \\
125.8 \\
136.6\end{array}$ & $\begin{array}{l}159.0 \\
169.9 \\
186.6 \\
188.6 \\
182.9\end{array}$ & $\begin{array}{l}224.10 \\
204.20 \\
219.30 \\
222.80 \\
226.20\end{array}$ & $\begin{array}{r}109.5 \\
94.0 \\
108.8 \\
105.1 \\
110.3\end{array}$ & $\begin{array}{l}165.4 \\
177.7 \\
193.5 \\
187.7 \\
184.8\end{array}$ & $\begin{array}{l}212.7 \\
204.9 \\
207.0 \\
189.6 \\
212.0\end{array}$ & $\begin{array}{l}118.8 \\
107.4 \\
122.0 \\
125.6 \\
141.2\end{array}$ & $\begin{array}{l}160.2 \\
167.6 \\
193.4 \\
188.0 \\
180.6\end{array}$ & $\begin{array}{l}211.6 \\
199.9 \\
205.9 \\
161.3 \\
157.6\end{array}$ & $\begin{array}{r}112.2 \\
90.4 \\
107.3 \\
118.7 \\
109.3\end{array}$ & $\begin{array}{l}165.2 \\
172.0 \\
195.2 \\
190.6 \\
191.2\end{array}$ & $\begin{array}{l}220.3 \\
210.8 \\
206.4 \\
165.4 \\
165.4\end{array}$ & $\begin{array}{r}1.5 \\
.6 \\
.9 \\
1.1 \\
2.8\end{array}$ \\
\hline \multicolumn{14}{|c|}{ Group LDD } \\
\hline $\begin{array}{l}1 \\
2 \\
3 \\
4 \\
5\end{array}$ & $\begin{array}{l}125.7 \\
137.5 \\
145.4 \\
154.4 \\
169.7\end{array}$ & $\begin{array}{l}117.9 \\
141.6 \\
166.6 \\
166.4 \\
242.0\end{array}$ & $\begin{array}{l}217.50 \\
231.30 \\
205.60 \\
231.00 \\
234.40\end{array}$ & $\begin{array}{l}110.7 \\
116.9 \\
124.9 \\
128.6 \\
137.2\end{array}$ & $\begin{array}{l}109.9 \\
128.2 \\
140.6 \\
176.0 \\
242.8\end{array}$ & $\begin{array}{l}208.7 \\
230.7 \\
215.8 \\
241.7 \\
251.9\end{array}$ & $\begin{array}{l}113.5 \\
128.6 \\
144.1 \\
156.6 \\
149.3\end{array}$ & $\begin{array}{l}120.9 \\
136.7 \\
152.9 \\
182.4 \\
258.3\end{array}$ & $\begin{array}{l}208.7 \\
228.7 \\
205.2 \\
183.4 \\
148.6\end{array}$ & $\begin{array}{l}111.3 \\
115.7 \\
122.9 \\
120.2 \\
135.6\end{array}$ & $\begin{array}{l}113.7 \\
129.4 \\
145.2 \\
180.6 \\
236.6\end{array}$ & $\begin{array}{l}213.0 \\
230.0 \\
206.9 \\
160.9 \\
120.4\end{array}$ & $\begin{array}{l}.3 \\
.4 \\
.2 \\
.2 \\
.1\end{array}$ \\
\hline \multicolumn{14}{|c|}{ Group DLL } \\
\hline $\begin{array}{l}1 \\
2 \\
3 \\
4 \\
5\end{array}$ & $\begin{array}{r}72.9 \\
92.4 \\
100.0 \\
119.8 \\
127.1\end{array}$ & $\begin{array}{l}124.6 \\
204.1 \\
202.0 \\
234.2 \\
276.5\end{array}$ & $\begin{array}{l}188.96 \\
228.00 \\
201.20 \\
204.00 \\
202.40\end{array}$ & $\begin{array}{r}76.3 \\
80.5 \\
90.0 \\
105.8 \\
111.8\end{array}$ & $\begin{array}{l}130.8 \\
200.4 \\
217.5 \\
224.5 \\
268.7\end{array}$ & $\begin{array}{l}181.6 \\
211.8 \\
204.3 \\
222.2 \\
225.0\end{array}$ & $\begin{array}{r}78.2 \\
96.6 \\
102.6 \\
119.5 \\
126.8\end{array}$ & $\begin{array}{l}127.7 \\
155.4 \\
209.4 \\
248.0 \\
322.6\end{array}$ & $\begin{array}{l}182.6 \\
207.6 \\
179.1 \\
143.2 \\
106.0\end{array}$ & $\begin{array}{r}81.9 \\
81.1 \\
78.1 \\
105.2 \\
110.6\end{array}$ & $\begin{array}{l}132.5 \\
199.0 \\
193.6 \\
230.6 \\
267.8\end{array}$ & $\begin{array}{l}188.4 \\
216.6 \\
187.0 \\
116.3 \\
102.8\end{array}$ & $\begin{array}{l}.0 \\
.0 \\
.1 \\
.0 \\
.0\end{array}$ \\
\hline \multicolumn{14}{|c|}{ Group DLD } \\
\hline $\begin{array}{l}1 \\
2 \\
3 \\
4 \\
5\end{array}$ & $\begin{array}{r}138.8 \\
52.8 \\
76.8 \\
51.4 \\
77.4\end{array}$ & $\begin{array}{r}77.1 \\
93.5 \\
92.8 \\
97.5 \\
111.4\end{array}$ & $\begin{array}{l}129.70 \\
103.10 \\
170.60 \\
164.50 \\
167.30\end{array}$ & $\begin{array}{r}67.1 \\
77.5 \\
100.4 \\
99.5 \\
88.3\end{array}$ & $\begin{array}{r}82.2 \\
90.8 \\
121.6 \\
152.3 \\
141.3\end{array}$ & $\begin{array}{l}164.4 \\
188.5 \\
203.7 \\
204.1 \\
210.9\end{array}$ & $\begin{array}{r}78.3 \\
83.5 \\
102.6 \\
101.2 \\
88.7\end{array}$ & $\begin{array}{r}76.4 \\
95.0 \\
120.6 \\
152.0 \\
153.0\end{array}$ & $\begin{array}{l}164.3 \\
166.7 \\
136.2 \\
102.8 \\
108.6\end{array}$ & $\begin{array}{l}73.7 \\
76.6 \\
99.6 \\
95.8 \\
86.0\end{array}$ & $\begin{array}{r}80.2 \\
96.1 \\
113.2 \\
154.5 \\
142.8\end{array}$ & $\begin{array}{l}170.1 \\
168.6 \\
141.9 \\
115.6 \\
111.4\end{array}$ & $\begin{array}{l}.4 \\
.2 \\
.3 \\
.5 \\
.7\end{array}$ \\
\hline \multicolumn{14}{|c|}{ Group DDL } \\
\hline $\begin{array}{l}1 \\
2 \\
3 \\
4 \\
5\end{array}$ & $\begin{array}{l}114.9 \\
134.0 \\
134.3 \\
146.4 \\
158.3\end{array}$ & $\begin{array}{l}90.0 \\
95.6 \\
92.6 \\
96.6 \\
90.2\end{array}$ & $\begin{array}{l}213.20 \\
216.00 \\
201.30 \\
210.50 \\
200.30\end{array}$ & $\begin{array}{r}95.5 \\
118.4 \\
134.6 \\
148.5 \\
133.7\end{array}$ & $\begin{array}{r}93.1 \\
88.3 \\
97.0 \\
121.4 \\
94.6\end{array}$ & $\begin{array}{l}193.2 \\
215.5 \\
211.5 \\
220.6 \\
227.8\end{array}$ & $\begin{array}{l}122.3 \\
128.9 \\
132.3 \\
147.0 \\
145.3\end{array}$ & $\begin{array}{l}89.3 \\
95.5 \\
73.4 \\
96.5 \\
86.9\end{array}$ & $\begin{array}{l}198.0 \\
196.3 \\
156.3 \\
151.0 \\
119.8\end{array}$ & $\begin{array}{l}100.8 \\
105.6 \\
126.9 \\
151.2 \\
121.0\end{array}$ & $\begin{array}{r}100.1 \\
97.1 \\
93.5 \\
102.7 \\
72.0\end{array}$ & $\begin{array}{l}215.9 \\
195.4 \\
143.4 \\
126.2 \\
121.0\end{array}$ & $\begin{array}{r}.1 \\
.1 \\
.9 \\
1.3 \\
1.2\end{array}$ \\
\hline \multicolumn{14}{|c|}{ Group DDD } \\
\hline $\begin{array}{l}1 \\
2 \\
3 \\
4 \\
5\end{array}$ & $\begin{array}{l}170.0 \\
203.6 \\
197.3 \\
190.0 \\
171.0\end{array}$ & $\begin{array}{l}163.4 \\
198.0 \\
229.4 \\
246.9 \\
272.8\end{array}$ & $\begin{array}{l}259.60 \\
300.90 \\
319.30 \\
299.10 \\
279.60\end{array}$ & $\begin{array}{l}142.4 \\
162.8 \\
121.2 \\
173.9 \\
163.0\end{array}$ & $\begin{array}{l}189.4 \\
197.2 \\
238.2 \\
285.1 \\
286.2\end{array}$ & $\begin{array}{l}264.1 \\
293.2 \\
298.7 \\
293.0 \\
299.5\end{array}$ & $\begin{array}{l}179.0 \\
190.6 \\
203.8 \\
127.5 \\
171.3\end{array}$ & $\begin{array}{l}182.4 \\
196.8 \\
233.3 \\
258.3 \\
264.8\end{array}$ & $\begin{array}{l}261.2 \\
249.8 \\
219.6 \\
184.6 \\
156.0\end{array}$ & $\begin{array}{l}150.0 \\
166.8 \\
172.4 \\
172.2 \\
154.6\end{array}$ & $\begin{array}{l}236.7 \\
211.6 \\
239.0 \\
265.8 \\
286.2\end{array}$ & $\begin{array}{l}287.0 \\
274.6 \\
218.8 \\
172.6 \\
144.1\end{array}$ & $\begin{array}{r}.4 \\
.3 \\
.5 \\
.5 \\
1.0\end{array}$ \\
\hline
\end{tabular}

ing performance, except, of course, rate to the comparison stimuli.

\section{DISCUSSION}

The present results may be summarized as follows. First, dark delay intervals were found to produce better conditioning than illuminated delays, but only when the sample and comparison stimuli were presented with the chamber illuminated. When the stimuli were presented with the chamber darkened, delay interval illumination did not affect conditioning. Second, presenting sample and comparison stimuli in an illuminated chamber produced better conditioning than presenting the stimuli with the chamber darkened, although this effect interacted with the delay interval and with sessions by the intertrial interval. Third, the interaction of Sessions by Intertrial Interval by Stimulus Presentation shows that constant illumination between the stimuli and the ITI resulted in better conditioning than when illumination conditions differed between the stimuli and the ITI. Conditions of 
Table 3

Responses per Minute: Means for the Stimulus Presentations by Delay Interval Interaction Across Blocks of Five Sessions (B/S)

\begin{tabular}{|c|c|c|c|c|c|}
\hline $\mathrm{B} / \mathrm{S}$ & Samples & Delay & $\mathrm{S}+$ & S- & ITI \\
\hline \multicolumn{6}{|c|}{ Condition LL } \\
\hline$\dot{1}$ & 111.7 & 121.5 & 200.1 & 195.7 & .4 \\
\hline 2 & 126.8 & 183.7 & 236.4 & 183.6 & .6 \\
\hline 3 & 127.8 & 221.4 & 219.9 & 144.2 & 1.2 \\
\hline 4 & 135.3 & 250.9 & 229.7 & 109.8 & 2.1 \\
\hline 5 & 143.6 & 294.7 & 233.6 & 92.6 & 3.4 \\
\hline \multicolumn{6}{|c|}{ Condition LD } \\
\hline 1 & 92.7 & 75.1 & 144.1 & 142.6 & .4 \\
\hline 2 & 79.4 & 83.6 & 166.7 & 132.3 & .2 \\
\hline 3 & 98.5 & 94.4 & 185.9 & 95.9 & .2 \\
\hline 4 & 105.3 & 110.4 & 198.0 & 75.0 & .3 \\
\hline 5 & 105.5 & 107.2 & 198.0 & 75.0 & .4 \\
\hline \multicolumn{6}{|c|}{ Condition DL } \\
\hline 1 & 111.3 & 127.8 & 210.8 & 211.4 & .8 \\
\hline 2 & 109.8 & 132.9 & 210.2 & 200.6 & .4 \\
\hline 3 & 123.8 & 140.6 & 209.8 & 178.0 & .9 \\
\hline 4 & 133.5 & 146.5 & 210.9 & 151.0 & 1.2 \\
\hline 5 & 132.0 & 135.4 & 216.6 & 140.9 & 2.0 \\
\hline \multicolumn{6}{|c|}{ Condition DD } \\
\hline 1 & 137.8 & 154.3 & 237.5 & 242.5 & .4 \\
\hline 2 & 152.8 & 167.4 & 264.0 & 245.8 & .4 \\
\hline 3 & 154.0 & 193.2 & 259.8 & 212.6 & .4 \\
\hline 4 & 153.0 & 220.2 & 266.2 & 175.4 & .4 \\
\hline 5 & 156.5 & 261.2 & 266.4 & 142.3 & .6 \\
\hline
\end{tabular}

Note-L $=$ houselight on, $D=$ houselight off; first position= stimulus presentations, second position = delay interval; $S_{+}^{+}=$ matching comparison stimuli, $S-=$ nonmatching comparison stimuli.

constant dark and changing illumination produced similar decrements in performance, although illuminated stimulus presentations with dark ITIs was shown to promote slightly better performance than constant dark or dark stimulus presentations with illuminated ITIs.

According to D'Amato (1973), dark delay intervals enhance performance of short-term memory tasks relative to illuminated delay intervals. However, the present result indicates that acquisition of DMTS is enhanced by dark delays only when the DMTS stimuli are presented in an illuminated chamber. Moreover, even though the improved performance with dark delay intervals was statistically significant, the actual differences between the discrimination ratios were marginal, $62.53 \%$ with illuminated delays and $64.66 \%$ with dark delays. It may be that delay intervals longer than the $1 \mathrm{sec}$ used in this experiment would produce greater differences. Nonetheless, further speculation regarding such small differences is not warranted.

The primary result of the present experiment was the three-way interaction between the sessions, the intertrial interval, and the stimulus presentations. This interaction provides general support for Wasserman's (1973) cue localization hypothesis, in which the presentation of keylight stimuli in a dark chamber retards conditioning to the keylights. In the present experiment, those conditions in which the stimuli were presented in an illuminated chamber (LL and DL) produced better performance than those conditions in which the stimuli were presented in a dark chamber (LD and DD). The one exception to this finding was that the DL condition was superior to DD but only in the last block of sessions. This suggests that illuminated stimulus presentations by themselves do not support better conditioning.

Wagner's (1979) notion that a salient stimulus change commands an animal's attention in shortterm memory and displaces the current contents of a limited-capacity rehearsal buffer is particularly relevant to the present experiment. The combination of Wagner's notion with Wasserman's cue localization hypothesis suggests that the positive effect of the illuminated chamber may have been negated by the deleterious effect of the stimulus change in the DL condition. Combining these two positions into a "cue localization and stimulus change" hypothesis is especially attractive because the ordering of the four conditions is then predicted, albeit post hoc. For example, it may be that the LL condition resulted in the best performance because no stimulus change occurred and because the chamber was illuminated during stimulus presentations. That the birds in the DL

Table 4

Responses per Minute: Means for the ITI by Stimulus Presentations by Sessions Interaction

\begin{tabular}{|c|c|c|c|c|c|}
\hline $\mathrm{B} / \mathrm{S}$ & Sample & Delay & St & S- & ITI \\
\hline \multicolumn{6}{|c|}{ Condition LL } \\
\hline 1 & 121.0 & 92.7 & 178.1 & 162.0 & .6 \\
\hline 2 & 126.1 & 125.5 & 220.2 & 123.4 & .6 \\
\hline 3 & 132.6 & 157.0 & 210.8 & 79.0 & 1.2 \\
\hline 4 & 140.8 & 174.7 & 229.0 & 65.4 & 2.1 \\
\hline 5 & 147.0 & 191.3 & 230.2 & 60.4 & 3.5 \\
\hline \multicolumn{6}{|c|}{ Condition LD } \\
\hline 1 & 114.8 & 139.0 & 215.8 & 213.4 & .9 \\
\hline 2 & 111.2 & 152.9 & 217.8 & 217.4 & .5 \\
\hline 3 & 124.9 & 171.8 & 211.9 & 206.1 & .6 \\
\hline 4 & 129.4 & 182.5 & 221.3 & 167.8 & .7 \\
\hline 5 & 136.2 & 214.9 & 231.1 & 119.4 & 1.5 \\
\hline \multicolumn{6}{|c|}{ Condition DL } \\
\hline 1 & 83.4 & 103.9 & 166.2 & 176.4 & .2 \\
\hline 2 & 80.1 & 141.8 & 182.8 & 189.9 & .1 \\
\hline 3 & 93.8 & 158.8 & 195.0 & 161.1 & .2 \\
\hline 4 & 99.8 & 186.7 & 198.7 & 119.5 & .2 \\
\hline 5 & 102.1 & 210.5 & 201.4 & 107.2 & .4 \\
\hline \multicolumn{6}{|c|}{ Condition DD } \\
\hline 1 & 134.4 & 143.1 & 232.5 & 240.5 & .2 \\
\hline 2 & 151.3 & 146.3 & 256.4 & 229.0 & .2 \\
\hline 3 & 152.8 & 162.1 & 257.7 & 184.5 & .7 \\
\hline 4 & 157.2 & 184.2 & 255.8 & 158.6 & .9 \\
\hline 5 & 152.3 & 181.7 & 251.8 & 135.2 & 1.1 \\
\hline
\end{tabular}

Note- $L=$ houselight on, $D=$ houselight off: first position $=I T I$, second position $=$ stimulus presen tations; $S+=$ matching compar . ison stimuli, $S$ = nonmatching comparison stimuli. 
condition performed poorly in the beginning sessions may be attributed to the deleterious effect of stimulus change. The significant difference between the DL condition and the DD condition in the last five sessions may be attributed to the enhancing effect of presenting stimuli in an illuminated chamber. Condition DD did not involve a stimulus change, but these birds may have learned poorly because of the dark chamber during stimulus presentations. Finally, LD, with the poorest learning curve of all, suffered both a stimulus change and presentation of the keylight stimuli in the dark. This cue-localization and stimulus-change hypothesis therefore accounts nicely for the current results.

The cue-localization and stimulus-change account may be viewed as either a posttrial effect or a pretrial effect. According to Wagner's model, stimulus change is most critical in the ITI during consolidation of the previous trial. Maki (1979), however, has demonstrated that posttrial illumination changes do not interfere with the formation of simple discriminations. It is not discernible from the present experiment whether the illumination change between the ITI and the stimulus presentations disrupted a consolidation process at trial's end or disrupted encoding of the sample stimuli at the trial's beginning. Posttrial vs. pretrial effects are not necessarily mutually exclusive. It is possible that posttrial stimulus changes degrade consolidation of the previous trial and that pretrial stimulus changes degrade encoding of the upcoming trial events. Therefore, it may be that the present results reflect an interaction of pre- and posttrial effects. Further research is required to separate the relative detrimental effects of pre- and posttrial stimulus changes on the formation of long-term memories. One simple possibility may be to present illumination and darkness during the first rather than the second half of the ITI. If the stimulus change occurs early in the ITI, with no changes between the end of the ITI and the next trial, then posttrial disruption may be assessed independently of pretrial disruption. A similar procedure may be employed for assessing pretrial effects independently of posttrial effects.

\section{REFERENCES}

Cook, R. G. Retroactive interference in pigeon short-term memory by a reduction in ambient illumination. Journal of Experimental
Psychology: Animal Behavior Processes, 1980, 6, 326-338.

D'Amato, M. R. Delayed matching and short-term memory in monkeys. In G. H. Bower (Ed.), The psychology of learning and motivation: Advances in research and theory (Vol. 7). New York: Academic Press, 1973.

D'Amato, M. R., \& O'Neil, W. Effect of delay-interval illumination of matching behavior in the Capuchin monkey. Journal of the Experimental Analysis of Behavior, 1971, 15, 327-333.

ETKIN, M. W. Light-produced interference in a delayed matching task with Capuchin monkeys. Learning and Motivation, 1972, 3, 313-324.

Grant, D. S., \& Roberts, W. A. Sources of retroactive inhibition in pigeon short-term memory. Journal of Experimental Psychology: Animal Behavior Processes, 1976, 2, 1-16.

Hearst, E. Pavlovian conditioning and directed movements. In G. Bower (Ed.), The psychology of learning and motivation (Vol. 9). New York: Academic Press, 1975.

Hearst, E., \& Jenkins, H. M. Sign-tracking: The stimulusreinforcer relations and directed action. Austin, Tex: Psychonomic Society, 1974.

KIRK, R. E. Experimental design: Procedures for the behavioral sciences. Belmont, Calif: Brooks/Cole, 1968.

Maki, W. S. Discrimination learning without short-term memory: Dissociation of memory processes in pigeons. Science, 1979, 204, 83-85.

Rescorla, R. A., \& Wagner, A. R. A theory of Pavlovian conditioning: Variations in the effectiveness of reinforcement and non-reinforcement. In A. H. Black \& W. F. Prokasy (Eds.), Classical conditioning II: Current research and theory. New York: Appleton-Century-Crofts, 1972.

Roberts, W. A., \& Grant, D. S. An analysis of light-induced retroactive inhibition in pigeon short-term memory. Journal of Experimental Psychology: Animal Behavior Processes, 1978, 4, 219-236.

Shimr, C. P., \& Moffitт, M. Short-term memory in the pigeon: Delayed-pair-comparison procedures and some results. Journal of the Experimental Analysis of Behavior, 1977, 28, 13-25.

Tomie, A., MurPhy, A. L., Fash, S., \& Jackson, R. L. Retardation of autoshaping following pretraining with unpredictable food: Effects of changing the context between pretraining and testing. Learning and Motivation, 1980, 11, 117-134.

Tranberg, D. K., \& Rilling, M. Delay interval illumination changes interfere with pigeon short-term memory. Journal of the Experimental Analysis of Behavior, 1980, 33, 39-49.

WAGNeR, A. R. Habituation and memory. In A. Dickinson \& R. A. Boakes (Eds.), Mechanisms of learning and motivation: A memorial volume to Jerzy Konorski. Hillsdale, N.J: Erlbaum, 1979.

Wasserman, E. A. The effect of redundant contextual stimuli on autoshaping the pigeon's keypeck. Animal Learning \& Behavior, 1973, 1, 198-206.

Zentall, T. R. Memory in the pigeon: Retroactive inhibition in a delayed matching task. Bulletin of the Psychonomic Society, 1973, 1, 126-128.

(Received for publication August 27, 1980; revision accepted December 15, 1980.) 